\title{
Agreement at PF: An Argument from Partial Control
}

\author{
Idan Landau \\ idanl@bgu.ac.il
}

\begin{abstract}
Controlled null subjects (PRO) are semantically bound variables that bear morphological features. In certain environments of partial control, the morphological $\phi$-features (specifically, [person]) and the semantic value of PRO diverge. A natural explanation of the fact that the [person] feature of PRO is uninterpreted is that it is assigned at PF. Given that this feature participates in agreement relations, we conclude that agreement must be (optionally or exclusively) a PF phenomenon.
\end{abstract}

\section{Introduction}

The recent decade has seen intensive research on the topic of grammatical agreement from various angles. Among the issues that attract attention are configurational constraints on agreement (locality and intervention), morphological consequences (spellout and impoverishment) and semantic implications (feature valuation and interpretability).

A fundamental question, which bears on all of these issues, is an architectural one: What is the locus of agreement? Where in the grammar does it apply? The question and the issues surrounding it are not new, but within Minimalism they seem to present themselves with particular acuity, centering on the elementary operation Agree. Although it is clear that the realization of formal features like [person] or [case] is sensitive to syntactic configurations, it is less obvious whether the actual values that these features take on are determined within the core syntactic component or rather within interfacing components like PF or LF.

The architectural and the technical questions turn on real empirical issues. The syntax/semantics view of agreement entails that the outcome of agreement processes (i.e., feature valuation) should somehow reveal itself in genuine syntactic or semantic consequences. The PF view of agreement, on the other hand, entails that feature valuation should have no effect whatsoever on syntactic phenomena or semantic interpretation. This is because the PF branch does not feed back into the syntactic 
derivation. Conversely, the syntax/semantics view isolates Agree from purely morphological information, while the PF view readily countenances the possibility of Agree being sensitive to such information.

a. Predictions of the syntax/semantics view of agreement

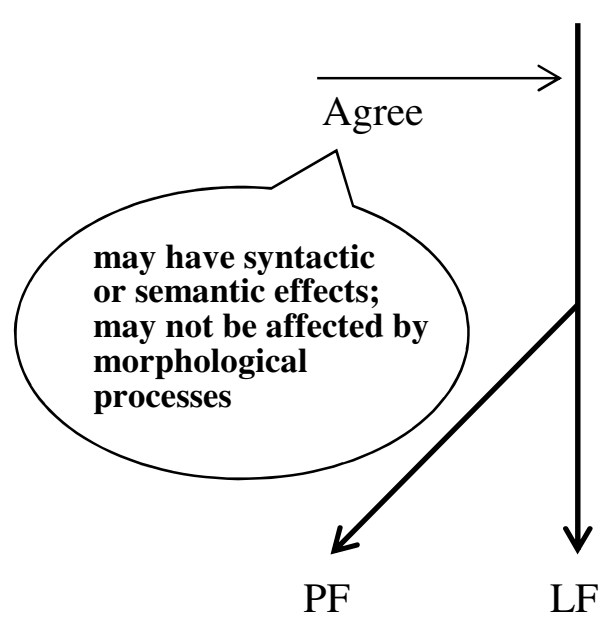

b. Predictions of the PF view of agreement

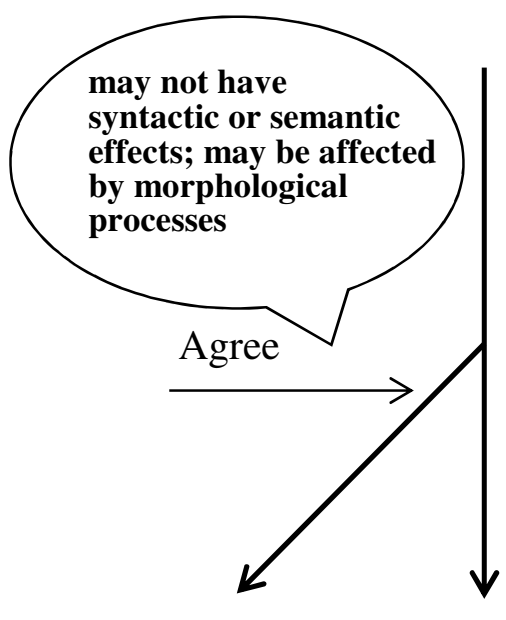

$\mathrm{PF}$

Proponents of the syntactic view of agreement argue that a number of grammatical phenomena cannot be adequately described or explained if agreement were to apply solely at the PF component. For example: (i) certain agreement patterns arise from syntactic configurations that are only established at LF (Polinsky and Potsdam 2001); (ii) certain agreement relations result in valuation of interpretable features, hence must feed LF (Pesetsky and Torrego 2007); (iii) certain features that function as unvalued probes for agreement with one argument simultaneously restrict semantic selection of another argument (Adger and Harbour 2007). ${ }^{1}$

On the other hand, proponents of the PF view of agreement point to phenomena of a rather different sort, which are problematic for the syntactic approach. For example: (i) certain agreement relations or dependencies are informed - i.e., fed or bled - by the outcome of morphological processes, like the assignment of inherent case (Bobaljik 2008), specification of formal, uninterpretable gender (Sigurðsson 2006, 2009), or the insertion of special, non-default agreement morphology (Chung 2012), hence must be placed after them, at PF; (ii) in certain situations, like binding of pronominal

${ }^{1}$ The phenomenon of "pluractionality" (see McCloskey 1991, Cabredo Hofherr and Laca 2012), where verbal (number) agreement correlates with a plurality of events or situations, does not challenge the PF view of agreement. Pluractional number, an interpretable feature, may arise on the verb independently of agreement; or it may be a reflex of agreement with some covert event argument, which in turn feeds the semantics. Either way, there is no direct link between the morphological feature on the verb and LF. 
variables, morphologically valued $\phi$-features remain invisible to semantic interpretation (Heim 2008).

The two views are mutually inconsistent, hence one would like to explore decisive evidence for one or the other. It is, of course, conceivable that agreement is an "anywhere" operation, applying across grammatical modules, possibly displaying a different profile in each (see Wurmbrand 2012 and especially Bhatt and Walkow, to appear). I take it that as long as the more restrictive options have not been proven false beyond reasonable doubt, they are to be preferred over the "anywhere" alternative on restrictiveness grounds (i.e., they generate stronger predictions). The choice between the two restrictive options is, of course, empirical.

This paper seeks to contribute one further argument in favor of the PF view of agreement, by way of presenting decisive evidence. The argument to follow will be based on the observation that a (normally) interpretable feature emerging from morphological agreement is nevertheless ignored by the semantic interpretation. It is ignored, we will argue, precisely because it is assigned at PF, "too late" to have any semantic consequences. ${ }^{2}$ The relevant facts concern the interaction of obligatory control (OC) and agreement, particularly in the subtype of OC known as partial control.

The structure of this paper is as follows. Section 2 presents general evidence that $\phi$ features on bound lexical pronouns are uninterpreted, a fact that is readily understood if they are transmitted to bound variables at PF. Section 3 establishes that PRO in OC is semantically a bound variable and that its $\phi$-features are morphologically valued. Section 4 develops the core argument: In certain examples of Partial Control (PC), the morphological [person] feature of PRO is uninterpreted - supporting the PF view of agreement. This section also proposes that PC should be viewed as a kind of associative plural. Section 5 extends the discussion to Portuguese dialects, which offer the rare opportuninity of signaling PC readings in the morphology, owing to the availability of inflected infinitives. It is argued that the Portuguese facts are consistent either with a PF view of agreement, a syntactic one, or a hybrid of both. Section 6 explores the broader implications of these results for the theory of control, and in

\footnotetext{
${ }^{2}$ Any "PF theory of agreement" must spell out what it takes PF to be. I assume that PF is a richly structured grammatical system. At a minimum, it consists of four subcomponents: (i) a system that receives and manipulates syntactic structures in specified ways; this is where chain reduction, ellipsis, agreement and case assignment apply; (ii) a linearization algorithm, converting hierarchical structures to linear strings (iii) a morphological system, converting the string of terminals to a string of morphemes; (iv) a phonological system, translating the morphological string into phonetic symbols. The present paper solely concerns the first of these subsystems.
} 
particular the proper syntactic representation of OC complements. Section 7 concludes the paper.

\section{Morphological features on bound pronouns are uninterpreted}

The behavior of pronouns in quantiftied contexts has generated a debate in recent work. The contested issue is whether the $\phi$-features on such bound pronouns are interpreted by the semantics or rendered invisible to it. Before presenting the data of interest, let us adopt the standard assumption that pronouns that are not bound denote variables and that their $\phi$-features (e.g., [person:1]) restrict their range by means of a presupposition, introduced by a partial identity function. For example, the lexical entry for $1^{\text {st }}$ person in $(2 b)\left(s_{c}=\right.$ speaker in context $\left.c\right)$ contributes the presupposition (2c) to the sentence in $(2 a)$.
a. I am sick.
b. $\quad \llbracket \mathrm{I}_{3} \rrbracket^{\mathrm{g}, \mathrm{c}}=\lambda \mathrm{x}_{\mathrm{e}}: \mathrm{x}$ includes $\mathrm{s}_{\mathrm{c}} \cdot \mathrm{X}$
c. $\llbracket \mathrm{I}_{3}$ am sick $\rrbracket^{\mathrm{g}, \mathrm{c}}$ is defined if $3 \in \operatorname{dom}(\mathrm{g})$ and $\mathrm{g}(3)$ includes $\mathrm{s}_{\mathrm{c}}$.

Heim (2008) pointed out that in quantified contexts, bound pronouns and reflexives "lose" these presupposition and are treated as if they lacked any inherent $\phi$-feature.
(3) a. Only I did my homework.
b. Only Jane helped herself.

(3a) admits both a sloppy and a strict reading. On the sloppy reading, my is construed as a bound variable and the sentence means: "I did my homework and for every $\mathrm{x} \neq \mathrm{me}, \mathrm{x}$ didn't do $\mathrm{x}$ 's homework". Note that the presupposition (2b) is missing; if it were present, the sentence would have been trivially true in all situations in which the speaker did his/her own homework, regardless of what others did. 
(3b) only admits a bound variable reading. Once again, the presupposition that the helped person was a female is missing (e.g., if the domain includes Jane, Bill and Greg, and Jane helped herself but Bill and Greg didn't help themselves, the sentence is judged true but not trivial).

If $\phi$-features are morphologically present on bound variables, why are they not interpreted? One possible solution would have them present in the syntax and removed at LF (Stechow 2003, Reuland 2010). An alternative solution would treat these features as a reflex of agreement; the pronouns are born featureless (or more precisely, unvalued) and obtain $\phi$-values from their binders via a process of "feature transmission" that applies at PF, i.e., too late for the semantics to see it (Rullman 2004, Heim 2008, Kratzer 2009). This "constructivist" view, as Kratzer observes, is conceptually simpler and more in line with late-insertion models of morphology. ${ }^{3}$ It is this PF-view of feature transmission that I will defend and elaborate on in the subsequent sections.

There is, however, and alternative account of the facts, which adheres to the classical idea that pronominal $\phi$-features are always interpeted (Spathas 2010, Jacobson 2012). ${ }^{4}$ According to this account, the appearance of semantically inert $\phi$-features is systematically related to focus. In (3a), the focus-sensitive item only associates with $I$, and generates a set of alternatives to the asserted content (all of which are assumed to be false). The idea, then, is that the $\phi$-features on the bound pronoun are absent from these alternatives, so they do not trigger presupposition (2b). In other words, the focus valus of (3a) is something like $\{p \mid p=x \operatorname{did} x$ 's homework $\}$. At the same time, the pronominal $\phi$-features continue to contribute their regular meaning to the assertion value of the sentence, hence cannot be said to be semantically inert. ${ }^{5}$

The excision of $\phi$-features on bound pronouns from the focus value of a sentence is, as Jacobson (2012: fn. 12) admits, "not particularly satisfying", although it may be required for other cases as well (e.g., ellipsis resolution). But proponents of the interpretive view of bound pronouns point to additional evidence that challenges the feature transmission analysis. Let us briefly examine this evidence.

\footnotetext{
${ }^{3}$ There are important differences between Heim's and Kratzer's proposals: whether the $\lambda$-binder is introduced by a nominal expression or by a functional head, whether predication is involved in feature transmission, and the role of context shifters in long-distance binding of indexicals. Still, both would agree, I assume, that PRO in OC is a locally bound variable, which is the relevant point in the discussion to follow.

${ }^{4}$ I thank an anonymous reviewer for urging me to address this alternative.

${ }^{5}$ The implementation in Spathas 2010 is restricted to gender features, while that in Jacobson 2012 is general. Furthermore, the latter is a variable-free analysis, the former is not. These differences do not bear on the basic point in the text.
} 
The relevant examples involve nouns that are specified for neuter gender; e.g., koritsi 'girl' in Greek. A pronoun bound by (a QP headed by) such a noun may either bear neuter gender, "agreeing" with the binder, or the natural (semantic) gender of the binder.

(4) Kathe koritsi $\mathrm{i}_{\mathrm{i}}$ diakosmise to dhomatio $\mathrm{tu}_{\mathrm{i}} / \mathrm{tis}_{\mathrm{i}}$.

Every girl.NEU decorated the room its / her

'Every girli decorated her room.' $^{\text {d }}$

Spathas (2010:222-223) argues that the occurrence of tis 'her' cannot be explained on the feature transmission account because the binder does not bear any FEM feature. Therefore, this must be an inherently specified, interpreted gender feature, which restricts the domain of quantification to female individuals. The neuter pronoun $t u$ 'its', on the other hand, results from feature transmission, as in the Heim/Ktratzer account.

Note first that this makes the "interpretive" view dualist in a way that the PF view is not. Both recognize the necessity of feature transmission, but only the interpretive view claims that an independent option of binding inherently specified features is also needed. But is it truly needed? Clearly, the head noun koritsi can effectively restrict the domain of quantification in virtue of its natural gender. This must be true, or else the version of (4) with the neuter $t u$ would have ranged both over females and males, which it does not. This makes the FEM feature on tis redundant just as it would be in the scope of binders that do bear a grammatical FEM feature. The only remaining issue is morphological: how does the bound pronoun come to bear this FEM feature in (4)?

The natural suggestion is that semantic gender is visible to feature transmission. Indeed, a suggestion along these lines was already made by Percus (2006) on the basis of examples like (5).

(5) Only the professor ${ }_{i}$ decorated her $r_{i}$ room.

This sentence is judged false if some male individual decorated his room, indicating that the FEM feature on her is semantically inert, just like the $1^{\text {st }}$ person feature on the 
bound pronoun in (3a) and the FEM feature on the reflexive in (3b). Since English nouns like professor bear no grammatical gender, Percus suggests that a phonetically null, semantic gender feature is present on professor in (5), and it is this feature that is transmitted to the bound pronoun, to determine its shape as her. Exactly the same account can be given to parallel examples in Greek with gender-neutral nouns (e.g., dhikijoros 'lawyer', see Spathas 2010:224).

To flesh out the details a bit more, we may adopt the INDEX-CONCORD distinction, independently motivated by a range of mixed or hybrid agreement phenomena (see Wechsler and Zlatić 2000, 2003, and the recent adaptation in Danon 2013). In this dual system, CONCORD features (gender, number, case) on a noun reflect its morphological class/declension, whereas INDEX features (gender, number, person) reflect its referential or semantic range. The former are expressed in NP-internal concord on determiners and attributive adjectives, the latter are expressed in subjectpredicate agreement and binding. Importantly, the values of CONCORD and INDEX features are aligned in the default case, but mismatches are possible and do occur, revealing their co-existence.

By way of illustration, consider the noun deca 'children' in Serbo-Croatian, which is simultaneously specified [CONCORD fem.sg] and [INDEX nue.pl] (Wechsler and Zlatić 2000), thus showing mixed agreement.

(6) Ta dobra deca dolaze.
that.F.SG good.F.SG children come.3.PL
'Those good children came.'

Wechsler and Zlatic further show that mismatches are also possible at the interfaces between morphology and CONCORD and between semantics and INDEX. Relevant to us is the observation that subject-predicate agreement may fail to align with "pragmatic", extra-sentential agreement, which is sensitive to semantic features. The diminutive noun devojče 'girl' bears neuter gender both in CONCORD and INDEX, Hence, it triggers neuter agreement on a clausemate participle but can be anaphorically referred to, across sentences, by either a neuter or a feminine $(=$ the natural gender) pronoun. 


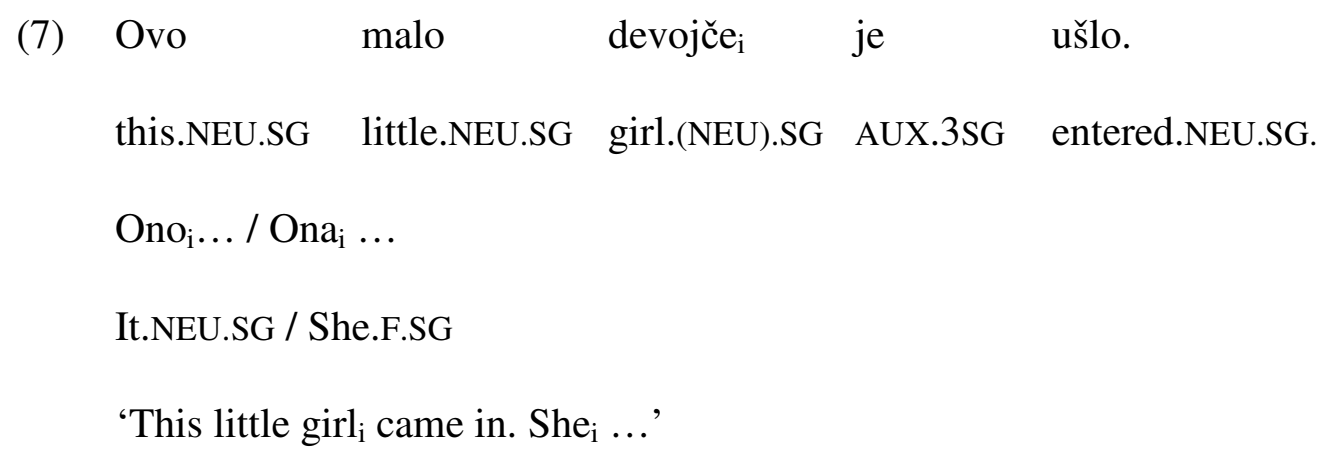

In light of these observations, the occurrence of the bound pronoun tis 'her' in (4) may well be the result of feature transmission targeting the semantic gender feature of koritsi 'girl'. 6 The alternation with $t u$ 'its' indicates that the INDEX gender feature is also available to the process. Crucially, neither feature is interpreted on the bound pronoun. This removes a potential argument for interpretable $\phi$-features on bound pronouns.

Finally, the case for the PF view of feature transmission is bolstered by separate set of facts, so far not considered. Heim (2008) and Kratzer (2009) mention examples that involve no focus at all, in which the bound pronoun must agree with its binder in morphological $\phi$-features, and mismatches are excluded even if semantically coherent.

(8) a. Nina respects herself / *myself.

(uttered by Nina)

b. They $y_{i}$ each thought they $/$ / $^{*} \mathrm{he}_{\mathrm{i}}$ had won.

\footnotetext{
${ }^{6}$ The INDEX gender feature of koritsi is probably neuter, as it triggers neuter agreement on predicates (Spathas 2010:223). This implies, pace Wechsler and Zlatić, that agreement under variable binding is not systematically keyed to the INDEX features the way subject-predicate agreement is. Obvious questions arise about mixing two or more types of agreement, that we have to set aside; see Wechler 2011.
} 
If Nina is the speaker in (8a) and they ranges over male individuals in (8b), the presuppositions of the bound myself and the bound he are satisfied, respectively. That these items are still excluded, therefore, is inexplicable on the interpretive view but follows automatically from the PF view, which requires morphological $\phi$-matching with the binder. ${ }^{7}$ Similar facts are cited by Reuland 2010 (from Menuzzi 1999). In Brazilian Portuguese, both nos and a gente designate $1^{\text {st }}$ person plural (nos is further ambiguous between a pronoun and a reflexive), but formally a gente is [person:3]. Variable binding configurations, which access semantic features for transmission (cf. (4)-(5)), may match the two pronouns (9a). ${ }^{8}$ Local anaphoric binding, however, is strictly anchored to the INDEX features (cf. (8a)), and consequently rejects such a mismatch (9b). Note that under a binder specified [person:1], nos Is licensed as a reflexive $(9 \mathrm{c})$.

(9) a. A gente acha que o Paolo já viu a gente/nos na TV.

We.3PL think.3PL that the Paolo already saw us.3PL/us.1PL on TV

'We think that Paolo has already seen us on TV.'

b. A gente devia se/*nos preparar para 0 prior.

We.3PL must REFL.3/REFL.1PL prepare.INF for the worst ${ }^{7}$ A case often discussed in this connection involves pronouns inside reversed specificational clefts,
bound by the subject. Note that the $1^{\text {st }}$ person feature on $m y$ is inert in the familiar way.

(i) I am the only one who handed in my homework on time.

Nevertheless, these cases display special properties that set them apart from the examples discussed in the text. First, the bound variable reading crucially depends on matching inflection on the embedded verb (Kratzer 2009). Second, [person] restores its semantic contribution in non-reversed specificational sentences while [gender] remains inert (Jacobson 2012). Thus, (ii) lacks a bound variable reading but (iii) has it.

(ii) The only one who handed in my homework on time was me.

(iii) The only one who handed in her homework on time was Sue.

I concur with Jacobson that neither a pure focus-based account nor a pure feature transmission account can explain these facts.

${ }^{8}$ The example in (9a) does not distinguish variable binding from coreference, but Reuland's discussion makes it clear that the relevant agreement facts hold for variable binding. 

c. Nós deviamos nos/*se preparar para o prior. We.1PL must REFL.1PL/REFL.3 prepare.INF for the worst 'We must prepare ourselves for the worst.'

Interesting questions arise as to the source of the contrast between local anaphors and non-locally bound variables (see Reuland 2001 for a principled account). The lesson for us, however, is quite simpe. There are many grammatical environments where semantic and morphological $\phi$-features are dissociated; in a subset of them, it is the morphological features that must surface on the bound variable and it is the perfectly coherent semantic features that cannot. This pattern supports the PF view of feature transmission.

In the next sections I show that feature transmission at PF can also explain a curious mismatch between the morphological features of PRO in OC and its semantic value. This case too falls outside the purview or the focus-based explanations and thus further tilts the balance against them.

\section{PRO in OC: Elementary semantics and morphology}

In this section it is established that PRO in OC is semantically a bound variable (section 3.1) and morphologically $\phi$-valued (section 3.2). In these respects it is entirely analogous to bound pronouns and therefore invites a parallel treatment.

\subsection{PRO in OC is a bound variable}

So far we have seen that morphological features of lexical (overt) pronouns are uninterpreted when the pronouns are used as bound variables; and that a natural account of this fact assumes that these (valued) features are transmitted to the bound pronouns at PF. 
An obvious question to ask at this point is whether null pronouns behave the same way or not. Here I will restrict my attention to the specific null pronoun (or pronounlike) element that occupies the subject position of controlled complements - PRO. ${ }^{9}$

That PRO in OC environments is interpreted as a bound variable is a classic observation (Morgan 1970, Fodor 1975). Relevant evidence consists of examples of the following sort.

(10) a. Nobody ${ }_{\mathrm{i}}$ agreed $\left[\mathrm{PRO}_{\mathrm{i}}\right.$ to take care of Jimmy].

b. [Only Richard $]_{\mathrm{i}}$ hated $\left[\mathrm{PRO}_{\mathrm{i}}\right.$ to play hip-hop].

c. Mary $\mathrm{i}_{\mathrm{i}}$ hoped $\left[\mathrm{PRO}_{\mathrm{i}}\right.$ to get a new car] and Claire did too.

PRO in (10a) is clearly a variable bound by the controller QP and does not carry any referential content of its own; the reading is: for no human $x$ in the context, [x agreed for $x$ to take care of Jimmy]. (10b) is not falsified if other people than Richard hated it when he played hip-hop, but only if they hated it when they themselves did so; this is the so-called sloppy reading characteristic of bound variables, and the absence of a strict reading indicates that OC PRO not only can but must be interpreted as a bound variable. Similarly, the elided VP in (10c) can only refer to Claire's hope that she herself would get a new car and not to her hope that Mary would.

\subsection{PRO in OC bears morphological features}

The next point to appreciate is that PRO does bear morphological features, and valued ones at that, despite their failure to project any phonetic exponence. The argument is based on simple parallels between phenomena of clause-bound agreement in finite clauses and in control clauses. Imagine that Mary speaks to John, so that in the speech context, $1^{\text {st }}$ person denotes Mary and $2^{\text {nd }}$ person denotes John. The following sentences that Mary says to John are all ungrammatrical in this context

\footnotetext{
${ }^{9}$ Not all generative analyses of control posit a syntactic element in the controlled position (e.g., Brame 1977, Evers 1988, Janke 2008; functional control in LFG, Bresnan 1982, Asudeh 2005, Falk 2006; Categorial Grammar, Dowty 1985; Conceptual Structure approaches, Jackendoff and Culicover 2003). Trivially, theories without (a counterpart of) PRO do not face any questions about the status of PRO's features. Such theories, however, face insurmountable difficulties, as the evidence for a syntactically active controlled element is compelling; see Landau 2013a:Ch.3 for extensive documentation.
} 
(11) a. * Everbody thinks [that Mary $\mathrm{y}_{\mathrm{i}}$ should be proud of myself $\mathrm{f}_{\mathrm{i}}$.

b. *Everbody thinks [that $\mathrm{John}_{\mathrm{i}}$ should be proud of yourself $\mathrm{i}$ ].

c. * Mary intended $_{\mathrm{i}} \mathrm{PRO}_{\mathrm{i}}$ to introduce myself $\left.\mathrm{f}_{\mathrm{i}}\right]$.

b. * Everybody urged $\mathrm{John}_{\mathrm{i}}\left[\mathrm{PRO}_{\mathrm{i}}\right.$ to be help yourself $\left.\mathrm{f}_{\mathrm{i}}\right]$.

Consider first (11a-b). Clearly, nothing is semantically wrong with these sentences: The embedded subject binds the embedded object and the presupposition triggered by the latter's person feature is satisfied. Rather, the sentences are morphologically illformed. As a bound variable, the reflexive object must inherit its $\phi$-features from its binder. Since the binder is $3^{\text {rd }}$ person, neither myself nor yourself is a possible spellout of the reflexive. Applying the same logic to (11c-d), we conclude that the embedded reflexive should have inherited [person:3] from its local binder and for that reason cannot surface as myselflyourself. But this implies that PRO, the local binder, indeed carries a valued person feature (and by extension, valued $\phi$-features).

One can run the same kind of argument for any other $\phi$-feature, reaching similar conclusions; e.g., since predicates agree with their associated DP and do so locally (i.e., never crossing clause boundaries), the obligatory plural marking -yim on the embedded predicate in the Hebrew example (12) reveals that PRO is also marked for number.

$$
\begin{aligned}
& \text { afilu ha-šamayim }{ }_{\mathrm{i}} \text { lo hixlixu }\left[\mathrm{PRO}_{\mathrm{i}}\right. \text { le'hera'ot yediduti-*(yim)]. } \\
& \text { even the-sky.DUAL not managed.PL to-look friendly-*(PL) }
\end{aligned}
$$

'Even the sky didn't manage to look friendly.'

Once again, semantic filtering is not relevant for such examples. The Hebrew noun šamayim 'sky' is morphologically dual but semantically singular, a kind of plurale tantum. Dual nouns trigger plural agreement in the language (there is no dedicated dual inflection on predicates), and so the [+dual] PRO transmits [+pl] to the embedded predicate. 
We also note the extensive evidence that PRO bears case features in languages where such features are detectable via concord with subject-oriented agreeing elements (see Landau 2008, Sigurðsson 2008 and Bobaljik and Landau 2009 for discussion and references).

Independent evidence that PRO is fully specified for morphological $\phi$-features exists in languages that evince OC into inflected complements. This is a heterogeneous group comprising subjunctive complements in Balkan languages, Persian and Hebrew (Landau 2004, Darzi 2008, Karimi 2008), inflected infinitives in Hungarian and Welsh (Tóth 2000, Tallerman 1998) and nominalized complements in Basque and Turkish (San-Martin 2004, Słodowicz 2007). A Persian example is given below.

$$
\begin{array}{llll}
\mathrm{Mæn}_{\mathrm{i}} & \text { mi-tun-æm } \quad\left[(\mathrm{ke}) \mathrm{PRO}_{\mathrm{i}}\right. & \text { næ-r-æm } & \text { xune }] . \\
\text { I } & \text { DUR-be.able-1SG (that) } & \text { not-go-1SG } & \text { home }
\end{array}
$$

'I am able not to go home.'

Under standard assumptions, overt inflection results from agreement with a $\phi$ specified local subject. This implies, without further ado, that the embedded, controlled null subject bears morphological $\phi$-features.

Putting together the evidence surveyed in the last two sections, we obtain the following conclusion.

$$
\text { OC PRO is a bound variable with valued morphological features. }
$$

In these respects, then, OC PRO is entirely parallel to the bound lexical pronouns discussed in section 2, and the natural question to ask is: Are the morphological features of PRO interpreted or not? Of course, the null hypothesis dictates that they should not be. Curiously, though, the question has rarely been put to empirical testing. ${ }^{10}$ The next section develops one test that bears directly on this question.

${ }^{10}$ Schlenker (2003) explicitly defends the idea that the morphological [person] feature of PRO is interpreted, although for theory-internal reasons he must assume that it is dissociated at LF from the gender (and presumably number) feature(s), the latter taking scope above the attitude verb, the former below it. Nevertheless, as far as I can tell, he does not offer any empirical argument against the 
Before we turn to the new test, we should dispense with one "pseudo-test", that does not, in fact, teach us anything about the semantic import of PRO's morphological features, although it is occasionally, and confusingly, taken to do so. Consider the well-known fact that the parallelism condition on VP-ellipsis is oblivious to mismatches in $\phi$-features.

(15) John wanted PRO to eat his lunch but we didn't want PRO to eat our lunch.

On the sloppy reading of (15), displayed in the struck-through continuation, the morphological features of both PRO and the possessive pronoun change from $\left[3^{\text {rd }}, \mathrm{Sg}\right.$, $\mathrm{M}]$ to $\left[1^{\mathrm{st}}, \mathrm{pl}\right]$. Suppose, as is sometimes assumed in the PF-deletion analysis of VPellipsis, that the elided conjunct is a full copy of its antecedent. Then the fact that the elided PRO is interpreted as $\left[1^{\text {st }}, \mathrm{pl}\right]$ in spite of carrying a morphological duplicate of $\left[3^{\text {rd }}, \mathrm{Sg}\right]$ could be taken as evidence that morphological features on PRO are uninterpreted.

The inference, however, is far from compelling. First, it presupposes that the VP tobe-elided is generated with feature values, whereas for all we know, it may well contain only feature types (perhaps valuation is a PF operation, and VPs that do not survive to Spellout are not morphologically valued); see Fox 2000, Safir 2004 and Merchant 2012 for proposals in this spirit. That verbal features (like tense and aspect) are copied unvalued in VP-ellipsis is quite clear from examples of the following sort (Lasnik 1995, Potsdam 1997, Wurmbrand 2012).

(16) a. John slept, and Mary will sleep/*slept too.

b. John was sleeping, and now Mary will sleep/*sleeping.

c. \% He might be attending the AA sessions,

I know his mother has been/*be attending the $\Lambda \Lambda$ sessions.

Second, even if feature values are generated, the deletion operation may subsequently delete them (why assume that PF-deletion only deletes phonetic exponences and not

alternative, $\mathrm{PF}$ view of agreement. The data in $(22 \mathrm{~b}-\mathrm{c})$ below seem to pose a challenge to Schlenker's account. 
morphological features too?), and do so just at the juncture of the PF/LF branches, so that the features are totally removed. Either way, there is no compelling reason to assume that any morphological features survive on the elided PRO at LF; perforce, there is no argument from ellipsis that PRO's morphological features are uninterpreted. ${ }^{11}$

\section{Morphological features on PRO in partial control}

In this section we will see evidence that PRO in partial control (PC) may bear morphological $\phi$-features that are not visible to semantic interpretation. This will serve as a new kind of argument for the PF view of agreeent.

The argument proceeds stepwise. Section 4.1 presents some basic properties of PC and proposes that PRO in such constructions is an associative plural, formed by a "group operator". Section 4.2 examines available methods to detect the [person] value of PC PRO and points out potential pitfalls. Section 4.3 then presents the crucial data in which the discrepancy between the morphological and the semantic values of [person] on PC PRO is attested. Finally, section 4.4 offers a formal, syntax-semantics characterization of the associative marker that produces PC and explains how the curious "mismatch" examples are generated.

\subsection{Partial Control: Basics}

One immediate argument that the $\phi$-features of PRO in OC are uninterpreted can be constructed in analogy to the examples in (3).
a. Only I wanted [PRO to do my homework].
b. Only Jane was prepared [PRO to help herself].

\footnotetext{
${ }^{11}$ Obviously, if VP-ellipsis is handled by LF-copying (rather than PF-deletion), no morphological features are copied with PRO, and again the issue of interpreting such features does not arise.
} 
Clearly, not only the $\phi$-features of my and herself are uninterpreted in these examples, but also those of PRO. Thus, (17a) does not mean: "I wanted to do my homework and for no $\mathrm{x} \neq \mathrm{me}$, $\mathrm{x}$ wanted me to do $\mathrm{x}$ 's homework". Rather, both PRO and my are featureless variables bound by only $I$ and ranging over both the speaker and nonspeakers.

There is a loophole in this argument, however. What makes PRO a bound variable is the quantificational nature of the controller (only I). Thus, one can blame the uninterpretable status of PRO's $\phi$-features in these examples on the same feature transmission operation applying between QPs and the pronouns they bind, recruited for (3) and (8).

What evidence do we have that PRO's $\phi$-features are uninterpreted even with a nonquantificational controller? The only potentially relevant example was (15), but unfortunately, we could not be sure that PRO bears any morphological features inside VP-ellipsis sites. What we need, then, is an independent argument for the uninterpretability of PRO's $\phi$-features even in non-quantified contexts. ${ }^{12}$

Such an argument indeed can be constructed on the basis of PC examples. In PC, PRO is understood to be a set including the controller and some additional participants salient in the context. ${ }^{13}$ These additional participants are often understood to be the speaker or hearer, a fact that will be utilized below to explore the interaction of PC with person marking. a. Having read our letter, $\mathrm{Bill}_{\mathrm{i}}$ agreed $\left[\mathrm{PRO}_{\mathrm{i}+}\right.$ to meet and talk
things over].

b. Fred was upset that Luise $_{i}$ regretted $\left[\mathrm{PRO}_{\mathrm{i}+}\right.$ kissing on the first date].

${ }^{12}$ Schlenker (2011) argues that the gender feature of OC PRO is uninterpreted on the basis of (i).

(i) John, a transsexual, hopes [PRO to become a woman and to buy himself/*herself a car].

Although John is a woman in each of the contexts compatible with his hopes, and PRO is semantically bound by the author coordinate of each of these contexts, it inherits masculine gender from the matrix controller. This seems to be a result of a semantically opaque rule of morphological agreement. On the other hand, it was Schlenker (2003) who previously proposed that the gender feature on PRO is interpreted, only outside the scope of the attitude operator, in a de re manner.

${ }^{13}$ See Wilkinson 1971 for the discovery of PC and Landau 2000 for extensive discussion of its distributional properties. PC was further studied and substantiated in Martin 1996, Wurmbrand 2001, 2002, Jackendoff and Culicover 2003, Barrie and Pittman 2004, Rodrigues 2007, Dubinsky and Hamano 2007, Landau 2008, Madigan 2008, Witkoś and Snarska 2009 and Modesto 2010a. A central question in these studies is how to demarcate the class of control predicates that license PC from those that do not. I will not address this issue here and simply focus attention on the agreement properties of PC. 
c. I tried hard but eventually failed to convince $\mathrm{Sam}_{\mathrm{i}}$

$\left[\mathrm{PRO}_{\mathrm{i}+}\right.$ to work together on the project].

Landau observed that PRO in such contexts is interpreted as a group name; although it continues to match the controller in syntactic number, it displays semantic plurality $[\mathrm{SP}]{ }^{14}$

(19) Bill told Sam that he's willing to work together / *become partners.

Landau assumed that the feature [SP] (or [Mereology]) is freely assigned to PRO in PC contexts. However, a more adequate analysis would trace the PC reading to a null associative morpheme (AM) that is attached to PRO, as in Madigan (2008). ${ }^{15}$ Note that plural controllers also admit a PC reading (as already recognized in Landau 2008), but this reading cannot be distinguished from the standard, exhaustive control (EC) reading on the basis of the [SP] feature, which is present on PRO in both cases.

a. They told me they $\mathrm{i}_{\mathrm{i}}$ agreed $\left[\mathrm{PRO}_{\mathrm{i}}\right.$ to meet]. $\quad E C$

b. They told $m_{\mathrm{j}}$ they $\mathrm{i}_{\mathrm{i}}$ agreed $\left[\left[\mathrm{PRO}_{\mathrm{i}}-A M\right]_{\mathrm{i}+\mathrm{j}}\right.$ to meet]. $\quad P C$

Unlike standard plurals, which are formed by a SUM operator, associative plurals are formed by a group operator (Kratzer 2009); we may take AM to denote just that operator. Applied to an index, AM yields a set consisting of the referent of this index and some salient referents "associated" with it (e.g., via family or social bonds, collegial status, etc.). Thus, the denotation of PC PRO is (21), where $i$ is the index of the controller. ${ }^{16}$

\footnotetext{
${ }^{14}$ As we will see in section 5, mismatch in syntactic number does occur in PC in Portuguese.

${ }^{15}$ On associative plurals, see Corbett 2000, Moravcsik 2003, Daniel and Moravcsik 2005 and Kratzer 2009. We will slightly adjust this assumption below and suggest that the infinitival verb, rather than PRO, is the host of AM.

${ }^{16}$ In Rodrigues 2004, 2007, the PC effect is also attributed to a null AM, with two important differences: (i) AM is taken to be a referential pro and not a group operator; (ii) the host of AM is a copy of the controller, as in the Movement Theory of Control. (i) implies that PC PRO is formed by summation, like standard plurals, ignoring ample typological evidence that associative plurals are morphologically and syntactically distinct from the former. Regarding the implications of (ii), see discussion in Landau 2013:167-168.
} 
(21) $\llbracket \mathrm{AM}(\mathrm{i}) \rrbracket^{\mathrm{g}, \mathrm{c}}=\{\mathrm{g}(\mathrm{i})\} \cup\{\mathrm{g}(\mathrm{n}) \mid \mathrm{g}(\mathrm{n})$ is salient and associated with $\mathrm{g}(\mathrm{i})$ in $\mathrm{c}\}$

Despite the presence of the AM (or [SP], in previous treatments), Landau argued that all syntactic $\phi$-features on PRO in PC must match those of the controller. Recent work by Sheehan (2012), however, challenges this claim, on the basis of novel data in English and in European Portuguese. Sheehan proposes that no feature matching is required in PC, the only condition being that the features specified on the controller and PRO are consistent with the inclusive interpretation.

Sheehan's empirical characterization of PC is at odds with Landau 2000 and her view of $\phi$-features is at odds with the present discussion. It is crucial for her account that $\phi$ features on PRO are interpreted, and owing to their denotation, allow certain mismatches but not others with the $\phi$-features on the controller.

I think that the weakening of Landau's empirical characterization of PC is not warranted, at least not for English, as the evidence below will show. That is, the [person] values on PRO and the controller always match in English PC (and in Portuguese PC too, for most speakers). If so, it will follow that Sheehan's data can only be explained on the assumption that morphological [person] on PRO is uninterpreted.

\subsection{Person in PC: setting the stage}

The following three examples are modeled on the basis of the data Sheehan considers (I return to the Portuguese data in section 5). Below each of them I indicate the readings of interest in italics.

a. I would like to go outside.

i. I would like us to go outside. 
b. Would you like to go outside?

i. Would you like it for you $_{p l}\left(=y_{\text {ou }}\right.$ sg + others $)$ to go outside?

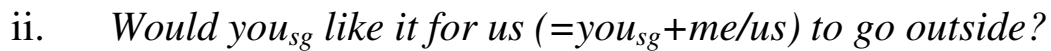

c. Would he like to go outside?

i. Would he $e_{i}$ like it for them (=him + others) to go outside?

ii. Would he like it for you $_{p l}\left(=\right.$ him $_{i}+$ you $\left._{s g} / p l\right)$ to go outside?

iii. Would he $e_{i}$ like it for us $\left(=\right.$ him $_{i}+$ me/us $)$ to go outside?

Of particular interest are the readings in (22b-ii) and (22c-ii,iii). In all three cases, PRO is understood to include a participant that ranks higher on the person hierarchy than the controller. Normally in such cases, spellout aligns with the higher person value, as shown by the forms of the embedded subject pronouns in the italicized readings. Within the framework of Heim 2008, this is the expected result. Following Rullman (2004), Heim considers plural pronouns (labeled "split-bound" pronouns) consisting of a bound subpart and a free subpart. The following example is adapted from these works.

(23) a. Every one of my ex-wives thinks we were a happy couple.

b. [Every one of $\mathrm{my}_{\mathrm{j}}$ ex-wives $]_{\mathrm{i}}$ thinks we $\mathrm{e}_{\mathrm{i}+\mathrm{j}}$ were a happy couple.

c. [Every one of $m y_{[j: 1]}$ ex-wives $]_{[i: 3]}$ thinks $\varnothing_{[\mathrm{i}: 3]+[\mathrm{j}: 1]}$ were a happy couple.

d. $\quad[\mathrm{i}: 1]$ or $[\mathrm{j}: 1] \rightarrow[\mathrm{i}+\mathrm{j}: 1]$

(23b) displays the split-bound reading of we in (23a), and is entirely parallel to (22ciii); note that the speaker, corresponding to the free subpart of we, is only mentioned for convenience (i.e., the possessive pronoun $m y$ ), and may just as well be picked directly from the deictic context (e.g., Every one of these women thinks we were a happy couple). (23c) displays Heim's analysis of the composite pronoun: The bound subpart, $i$, is endowed with the $3^{\text {rd }}$ person feature in virtue of feature transmission 
from its binder, while the referential, free subpart, $j$, is inherently endowed with the $1^{\text {st }}$ person feature. A morphological resolution algorithm comes into play in order to determine the overall person value of the plural pronoun. A natural assumption is that one component of this algorithm looks like (23d): Whenever a subpart of a pronoun is $1^{\text {st }}$ person, the whole pronoun is $1^{\text {st }}$ person. ${ }^{17}$ Together with the rule producing [plural] from a sum of singulars, this correctly spells out the split-bound pronoun $\varnothing_{[\mathrm{i}: 3]+[j: 1]}$ as we.

The question is whether the same feature resolution algorithm is at work in PC, effectively aligning the person value of the semantically plural PRO with its highestranking participant. ${ }^{18}$

To put it in concrete terms, we would like to know whether the proper morphosyntactic representation of (24a), under the PC reading in (24b), is (24c) or (24d).
a. Would you like to go outside?

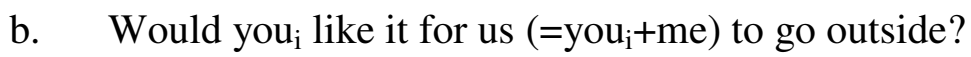
c. Would you sg $_{\text {gike }}\left[\left[\mathrm{PRO}_{[2 \mathrm{sg}]}-A M\right]_{[2 \mathrm{sg}]}\right.$ to go outside $]$ ?
d. Would you sg $_{\text {gike }}\left[\mathrm{PRO}_{[2 \mathrm{sg}]}-A M\right]_{[1 \mathrm{pl}]}$ to go outside $]$ ?

The choice, to recall, directly bears on our main concern - the (non)interpretability of $\phi$-features on PRO. If (24c) is the correct representation, then we have convincing evidence that a morphological [person:2] feature on PRO in OC is uninterpreted; it must remain uninterpreted, or else the only reading available would be (22b-i), i.e., the one excluding the speaker from the partially-controlled PRO (note that the sentence Would you like it for you (all) to go outside? cannot intend to include the speaker in the group going outside). On the other hand, if (24d) is the correct representation, as Sheehan (2012) maintains, then the morphological features and the semantic value of PRO coincide; PRO's $\phi$-features could be uninterpreted, but nothing precludes interpreting them, since they would give just the right semantics. This is so

\footnotetext{
17 This mirrors the ontological theorem that a sum of two individuals, one of which includes the speaker, also includes the speaker. Heim takes this PF-LF redundancy to be problem, which may be true, but does not weaken the evidential basis for (23d).

${ }^{18}$ Recall from (19) that syntactic number does not shift under PC in English.
} 
because in a context where $\llbracket \mathrm{PRO}-A M \rrbracket=\{$ you,I $\}$, presupposition $(2 \mathrm{~b})$, contributed by the morphological feature [person:1], is satisfied.

Furthermore, the person-resolution rule (23d) selects (24d) over $(24 \mathrm{c})$, since $1^{\text {st }}$ person trumps $2^{\text {nd }}$ person in composite pronouns.

Nonetheless, there is evidence that $(24 \mathrm{c})$ is the right representation of the PC reading in (24b) (possibly because the person-resolution rule fails to "see" the AM, see below). In fact, there is evidence that (24c) is the right representation of all PC readings of (24a), so that Landau's (2000) generalization holds: Neither number nor person features may be shifted in English PC. As indicated, this constitutes strong evidence that PRO's $\phi$-features are uninterpreted even in non-quantified contexts.

The evidence should be constructed with care. To argue that [person] is truly preserved in PC dependencies it is not enough to point to the ungrammaticality of person mismatches in examples like (25b).

(25) a. Arthur intended $\left[\mathrm{PRO}_{\mathrm{i}+}\right.$ to study together].

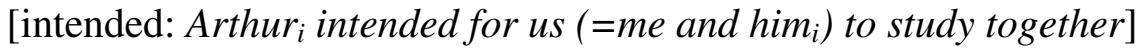

b. * Arthur $\mathrm{i}_{\mathrm{i}}$ intended [PRO $\mathrm{PR}_{\mathrm{i}+}$ to study by ourselves].

Despite that fact that PRO can be understood to denote the set $u s=\{$ Arthur,I $\}$, as shown in (25a), it cannot bind a first person reflexive in (25b). One should not conclude, however, that the mismatch in person is the cause of the problem here, since there is another mismatch - in syntactic number: the [plural] feature on ourselves is transmitted from PRO, but PRO is not allowed to differ in syntactic number from the controller, as shown in (19) (note that *I intended to study by ourselves is equally bad).

To isolate the effect of person mismatch, we should examine cases where syntactic number is preserved across the PC dependency. Even so, not all conceivable tests are informative. In particular, the most popular device of detecting [person] features binding of reflexive pronouns - imposes its own restrictions. Consider a typical PC example, (26a), with two of its potential readings, (26b) and (26c). 
(26) a. [John and his wife $]_{\mathrm{i}}$ would prefer $\left[\mathrm{PRO}_{\mathrm{i}+}\right.$ to discuss the matter further].

b. John and his wife would prefer for us (=John, his wife and me) to discuss the matter further.

c. John and his wife would prefer for them (=John, his wife and their kids) to discuss the matter further.

What (26b) shows is that the semantic person value of PRO in PC need not match the value of the controller. Once bound reflexives are introduced, however, such mismatches seem to be blocked: (27a) is ungrammatical and cannot have the reading (27b).

(27) a. * $*$ John and his wife $]_{\mathrm{i}}$ would prefer $\left[\mathrm{PRO}_{\mathrm{i}+}\right.$ to discuss ourselves $]$.

b. *John and his wife would prefer for us (= John, his wife and me) to discuss ourselves.

(27a) is a first indication that (24d) is not the correct representation of (24a). Despite the fact that a semantically $1^{\text {st }}$ person plural PC PRO is possible under a $3^{\text {rd }}$ person plural controller (see (26b)), it cannot bind a $1^{\text {st }}$ person plural reflexive. Unlike in (25b), [number] mismatch is also not at stake, both the controller and PRO being plural. The example is semantically perfect, hence it must be the morphological mismatch in the [person] values of the controller and PRO that is the culprit. ${ }^{19}$

But things are not that simple. If morphological feature matching were all that mattered for reflexive binding, one might expect a $3^{\text {rd }}$ person reflexive to be licensed instead of the $1^{\text {st }}$ person reflexive. This is not the case, as (28a) shows.

(28) a. * $*$ John and his wife $]_{\mathrm{i}}$ would prefer $\left[\mathrm{PRO}_{\mathrm{i}+}\right.$ to discuss themselves].

b. *John and his wife would prefer for us (= John, his wife and me) to discuss ourselves.

\footnotetext{
${ }^{19}$ As an anonimous reviewer points out, a consequence of this analysis is that $3{ }^{\text {rd }}$ person cannot be treated as absence of [person], for then nothing would be transmitted to PRO that would clash with the $1^{\text {st }}$ person feature on the bound reflexive.
} 

c. *John and his wife would prefer for them (= John, his wife and their kids) to discuss themselves.

Note that (28a) is only grammatical on an EC reading. The PC reading with a speakerincluding PRO (28b) is blocked, but even more interestingly, the pure, semantically $3^{\text {rd }}$ person PC reading (28c) is also blocked. Since (28c) involves neither a semantic nor a morphological mismatch between the person/number values of the controller and PRO, it must be ruled out by some specific condition on binding. Indeed, when no reflexive is involved, the intended readings of PC PRO are readily available, cf. $(26 b, c)$.

Variable binding involves coindexing. The fact that this coindexing is incompatible with PC suggests that the AM on PC PRO interferes with the process of indexical individuation. This restriction is plausibly rooted in the ontology of groups (as opposed to sums), which are accessed as collective individuals. Notice that PC PRO in general cannot be distributed over; (29a) lacks the reading easily available in (29b), where John's desire is for each member of the group denoted by the embedded subject to visit a different site. ${ }^{20}$

(29) a. $\mathrm{John}_{\mathrm{i}}$ wanted $\left[\mathrm{PRO}_{\mathrm{i}+}\right.$ to visit different sites].

b. John wanted them to visit different sites.

This semantic restriction on PC makes it rather difficult to use reflexive binding as a probe into the $\phi$-features of PRO in PC. Neverthless, the problem is soluble.

\footnotetext{
${ }^{20}$ Madigan (2008:139) observes that PC in Korean does allow distributive readings. This may either suggest that a second kind of [group] feature is available in Korean, whose output is not a collective individual (Madigan's proposal); or alternatively, that associative plurals in Korean are formed as in Chinese, by attaching a null pronoun to the "anchoring" nominal, creating a sum rather than a group. See also fn. 16.
} 


\subsection{Semantic and morphological [person] misaligned in PC}

Reflexive binding is the most direct way of detecting the morphological [person] value of PRO. But if PC PRO is incompatible with reflexive binding, how are we to pin down its morphological makeup?

A way out of the dilemma is to examine contexts where PRO is shared by two predicates - one facilitating the PC reading, the other diagnosing the [person] marking. This tactics is implemented below. Each example is accompanied by the intended reading below it, in italics (other readings are possible too, but irrelevant). The indicated readings reveal a divergence between the semantic value and the morphological [person] feature of the partially-controlled PRO, as the underlined titles indicate. Note that the controller, PRO and the embedded reflexive are all syntactically plural, thus no issues of number mismatch arise.

a. PC PRO: morphologically [3PL], semantically [1PL]

They wanted [PRO to prepare themselves and then meet for debate].

They wanted that they would prepare themselves and then we (= they and me/us) would meet for debate.

b. $\quad$ PC PRO: morphologically [3PL], semantically [2PL]

Thinking of you, I recommended to them [PRO to prepare themselves and convene at the earliest opportunity].

I recommended to them that they should prepare themselves and you ${ }_{P L}$ (= them and you guys) should convene at the earliest opportunity.

c. $\quad$ PC PRO: morphologically [3PL], semantically [1PL]

They preferred [PRO to cooperate looking pleased with themselves].

They preferred that we (they and me/us) would cooperate while they look pleased with themselves. 


\section{d. PC PRO: morphologically [2PL], semantically [1PL]}

Would you $_{\mathrm{PL}}$ (all) like [PRO to rehearse together before presenting yourselves]?

Would you like it for us (= you $\mathrm{u}_{\mathrm{PL}}$ and me/us) to rehearse together before you present yourselves?

A few words about the examples. The complement in (30a-b) contains conjoined predicates. Since the infinitival marker to is shared by the conjuncts, this must be a VP-level conjunction, hence the PRO subject is shared as well. ${ }^{21}$ The complement in (30c-d) contains an adjunct predicated of PRO (note that the adjunct should be construed with the downstairs reading). Predicative adjuncts reject PC (Landau 2007, 2013), e.g., *John took a shower before meeting in the city hall. Therefore, even if the gerundive adjuncts contain their own PRO subject, it is grammatically identical to the PC PRO subject of the infinitival complement, which is endowed with an associative morpheme.

In all four examples, then, what we see is a PRO element, which, in virtue of the PC reading, includes the speaker or hearer(s), and at the same time does not reflect this in its morphological signature. This is a rather striking state of affairs, in direct contradiction to (23d). Although a higher-ranked participant is included in the denotation of the PC PRO, its morphological [person] value must match the lowerrank value of the controller. Note that standard lexical plural pronouns never resolve person clashes in this manner. If I tell you 'Oh, they're zoologists', I cannot imply by that that either you or me are zoologists, nor can I imply that I'm a zoologist by saying 'Oh, you're all zoologists'.

\subsection{The syntax of PC: AM as a verbal affix}

A puzzling aspect of the examples in (30) is the fact a syntactically shared PRO subject appears to contribute to each conjunct in the complement a different denotation. On the relevant reading of (30a), for example, the semantic subject of

\footnotetext{
${ }^{21}$ Unless PRO remains VP-internal, as in some unconventional analyses (Baltin 1995), in which case each conjunct would host its own PRO subject and no conclusion could be drawn about the $\phi$-features of PC PRO. Control of adjuncts, however, as in (30c-d), requires a VP-external subject, on standard assumptions about the dependence of $\mathrm{OC}$ on c-command.
} 
prepare themselves is they while the semantic subject of meet for debate is us (=they + me/us). To fully understand how such examples are constructed by the grammar, we should be more explicit about the syntax of PC than we have been so far.

If PC boils down to a species of associative plurals, a sensible approach would be to model it on one of the mechanisms employed to obtain associative plurals in natural language. Consider then the fact that in many languages (e.g., Greek, Chilean Spanish, Plains Cree, the Talitsk dialect of Russian, Maltese and Haruai), associative plurals are directly marked on the verb. ${ }^{22}$ (31a) is a Maltese example from Corbett 2000:191, and (31b) is a Greek example (Anastasia Giannakidou, p.c.).

(31) a. Briangie / Brian gew.

Brian came.SG / Brian came.PL

'Brian came' / 'Brian and his family/friend(s) came.'

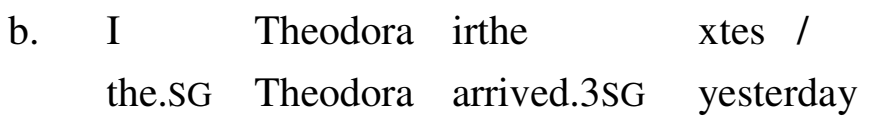

I Theodora irthan xtes.

the.SG Theodora arrived.3PL yesterday

'Theodora arrived yesterday' / 'Theodora and her family/friend(s) arrived yesterday'

Morphologically, this type of AM is homophonous with the [plural] verbal inflection. Semantically, however, it is a very different entity; not an uninterpretable reflex of agreement, but a semantically contentful morpheme. The function of this morpheme is to expand the subject argument of the predicate to a group. Given a "toy" VP like (32a), it delivers the denotation (32b) via the lexical entry in (32c), which supersedes our earlier version in (21). ${ }^{23}$

(32) a. [vp Bill [v'AM-left the house ]]

b. leave-the-house' (group(Bill'))

c. $\llbracket \mathrm{AM} \rrbracket=\lambda \mathrm{P}_{<\mathrm{et}>} \cdot \lambda \mathrm{x}_{\mathrm{e}} \cdot \mathrm{P}(\operatorname{group}(\mathrm{x}))$

\footnotetext{
${ }^{22}$ See Corbett 2000, Moravscik 2003 and Daniel \& Moravscik 2005.

${ }^{23}$ Technically, AM could be an affix on light $\mathrm{v}$, which would guarantee its proper application to the external argument.
} 
One immediate and welcome consequence of the verbal-affix view of AM is that it will remain null in uninflected contexts (i.e., contexts in which no inflectional affix is expressed); thus we explain why PC in infinitives has no visible morphological effect. Furthermore, languages in which control may be realized in inflected complements might be expected to provide the necessary morphological spellout for AM. Indeed, data from Portuguese suggests that this option exists, at least for some speakers; we turn to it in the next section.

Returning to the examples in (30), we can now explain the paradoxical appearance of a single syntactic subject contributing a different denotation to each conjunct. This is achieved by attaching the AM to one of the infinitival verbs but not to the other. A sentence like (30a) would have the following schematic structure, assuming ATBmovement of PRO (and suppressing irrelevant details).

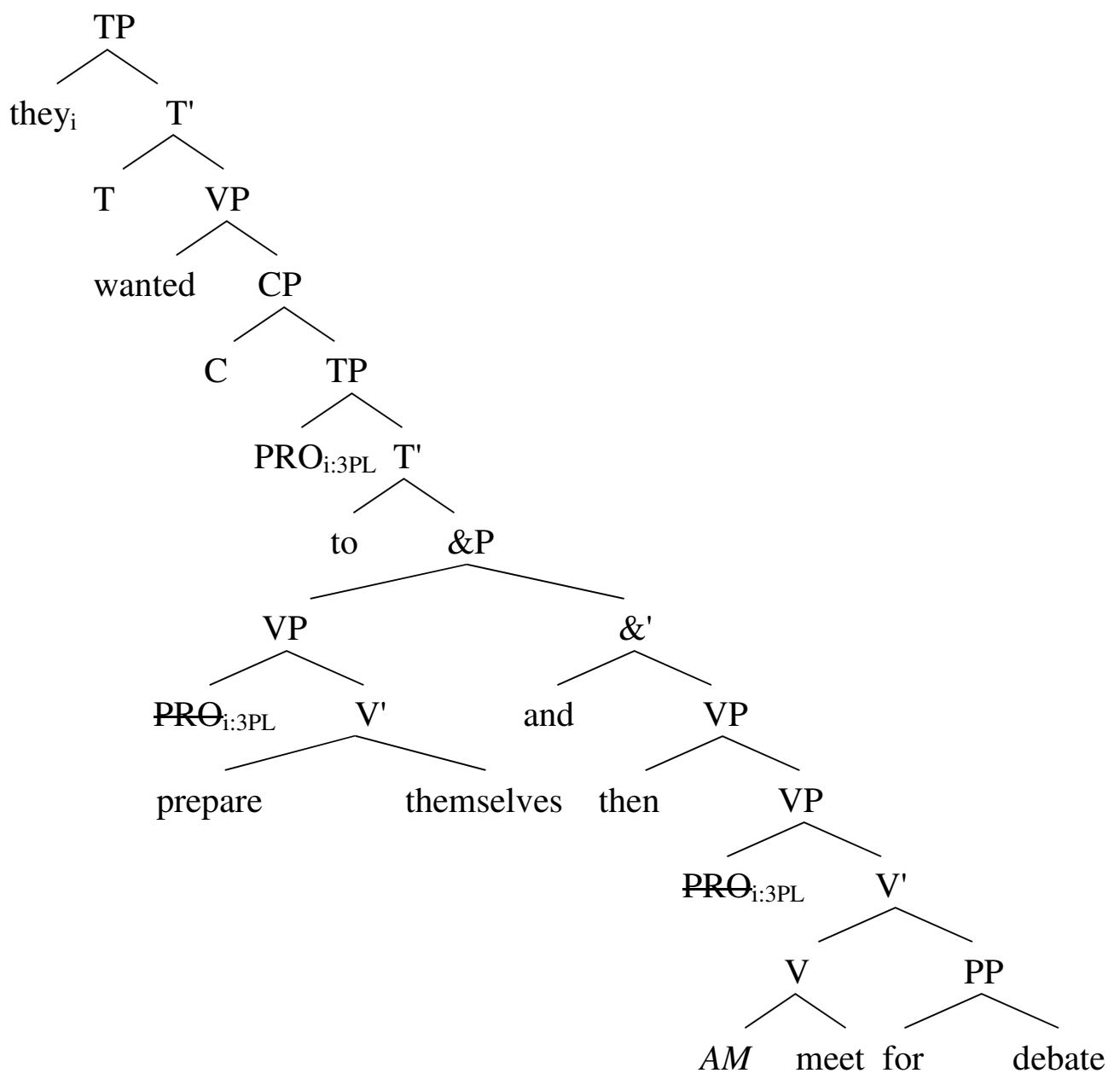


Each copy of PRO (marked with a strikethrough) is interpreted as a variable bound by they. In line with (14), each copy also bears the $\phi$-features transmitted to PRO, [3PL]. Crucially, the $3^{\text {rd }}$ person feature on the rightmost copy of PRO must remain uninterpreted on the speaker-including PC reading of (30a). Thus we have direct evidence for a mismatch between the semantic and morphological [person] values on PRO, consistent with the PF view of agreement.

One can pursue the implications of this conclusion in various ways. My purpose here is rather limited. What (30a-d) teach us is that morphological [person] must be preserved in English PC. Going back to (24), we now have strong evidence to choose (24c) over (24d) as the correct representation of the PC interpretation (24b). It follows that PRO in PC bears morphological person features that are uninterpreted.

In the absence of counterevidence, one would like to generalize this conclusion. First, [person] is uninterpreted in PC even when interpreting it would give indistinguishable semantic results (e.g., in (22a-i), (22b-i) and (22c-i)). Second, no $\phi$-feature is ever interpreted on PRO in OC environments. I take this general conclusion to be the ultimate outcome of applying the PF view of agreement to OC.

While we have not yet specified the mechanism by which PRO receives $\phi$-features at PF (see section 6 for some preliminary suggestions), it can easily be seen that the conclusion has immediate consequences for standard cases of agreement. PRO determines agreement on secondary predicates and clausal inflection (e.g., (12), (13)). If PRO's $\phi$-features are not valued before PF, as we concluded, it follows that these agreement processes cannot apply before PF either. ${ }^{24}$

\section{Person Value and Person Form Aligned: PC in Portuguese}

Consider again the PC example (34a), with its two potential analyses, (34c) and (34d).

a. Would you like to go outside?

\footnotetext{
${ }^{24}$ A more complicated solution would break agreement into two steps - feature-sharing and featurevaluation, as in Pesetsky \& Torrego 2007. Then an unvalued PRO may "agree" with an unvalued inflection, meaning the two come to share a single feature, which is only valued at PF. A decomposition of this sort is, in principle, compatible with our results, as long as the first step is also "pushed" to PF. It is, however, vital for Pesetsky \& Torrego to place feature-sharing in the syntax, as they claim it leads to interpretable effects. Such is not the present case, as we have seen.
} 


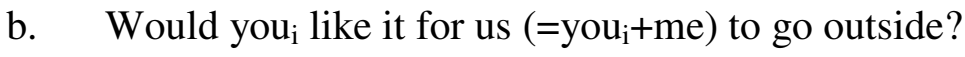
c. Would you sg $_{\text {g }}$ like $\left[\left[\mathrm{PRO}_{[2, \mathrm{sg}]}-A M\right]_{[2 \mathrm{sg}]}\right.$ to go outside $]$ ?
d. Would you sg $_{\text {g }}$ like $\left[\left[\mathrm{PRO}_{[2, \mathrm{sg}]}-A M\right]_{[1 \mathrm{p}]}\right.$ to go outside $]$ ?

On the basis of the agreement patterns in (30), we concluded that (34c) is the correct representation of (34a). That is, whenever the group formed by AM bears a person value distinct from the one transmitted to PRO from the controller, the latter prevails. It was also observed that, while supporting a PF view of agreement, this particular form of feature resolution is unlike the way feature conflicts are normally resolved on lexical pronouns (cf. (23)). Two questions arise, then: (i) Why is PC PRO resolved in this unusual way in English?, and (ii) Are there instances of PC where the feature conflict on PRO is resolved in the normal way?

Concerning question (i), we proposed that $\mathrm{AM}$ is a verbal affix on the infinitival verb. Because this verb is inherently uninflected, AM is morphologically invisible. A very different response is conceivable, however. One could take PC to be a wholly postsyntactic phenomenon, an inferential process of sorts, located in the semantic or pragmatic component (Hornstein 2003, Jackendoff and Culicover 2003, Pearson 2013), and for that reason, showing no effect on morphology. The problem with this view is that PC does have overt morphological impact in other languages, as will be shortly seen; see also Landau's 2008 observation that PC in Russian blocks case transmission. A solution divorced from syntax will not do.

Concerning question (ii), preliminary evidence from Brazilian Portuguese (BP) suggests a positive answer. In BP, OC may be realized in inflected complements. The verbal heads of such complements are capable of bearing an overt AM and thus transparently reflect the PC reading. Modesto (2010a) reports that infinitival complements in the language must be inflected for plural to allow a PC reading with predicates which are not inherently collective (plural marking is optional with collective predicates, like reunir 'meet').

$$
\begin{aligned}
& \text { A Dani decidiu } \mathrm{PRO}_{\mathrm{i}+} \text { viajar-em todos juntos. } \\
& \text { the Dani decided travel.INF-3PL all together.PL }
\end{aligned}
$$

'Dani decided that all of them should travel together.' 
According to Duarte, Gonçalves and Santos (2012) and Sheehan (2012), such sentences are also acceptable to some speakers of European Portuguese (EP). Recall that a mismatch in syntactic number under PC is not possible in English-type languages (cf. (19)).

Sheehan (2012) further reports that a mismatch in person value under PC is attested in inflected infinitives in European Portuguese (EP). Sentences like the following, with a third person controller and first person inflection on the infinitive, are accepted by about half the speakers. ${ }^{25}$

\% O João preferia reunirmo-nos mais tarde.
the João preferred.3SG meet.INF.1PL-self.1PL more late
'João ${ }_{i}$ would prefer for us (=him ${ }_{\mathrm{i}}+$ speaker) to meet later on.'

According to Sheehan, these are genuine OC examples (exhibiting a PC reading), however no evidence is adduced in support of this claim. Further doubts are cast by the fact that very similar examples (with a plural controller, minimizing the feature mismatch with PRO, hence the sentence should improve, if anything) are marked ungrammatical by linguists specializing in EP (Duarte, Gonçalves and Santos 2012).

$$
\begin{aligned}
& \text { * Os pais decidiram viajar-mos de comboio. } \\
& \text { The parents decided to.travel.INF-1PL by train } \\
& \text { 'The parents decided for us to travel by train.' }
\end{aligned}
$$

A survey I carried out among native speakers of EP obtained the following results. Out of 17 speakers, 14 completely rejected sentence (36). The three speakers who accepted it were then asked to judge a variant of the same sentence, containing the PP adjunct sem ele 'without him', where the pronoun is referentially dependent on the matrix subject João.

\footnotetext{
${ }^{25}$ Sheehan in fact holds that English data of the sort given in (22) display the same mismatch. This was shown to be false in the previous section. In addition, she argues that the $1^{\text {st }}$ person feature in the relevant English and EP examples is interpreted (hence, not a PF effect). The analysis to be offered below shows this to be an unnecessary assumption; PF feature transmission is fully consistent with the EP data.
} 
\% O João ${ }_{i}$ preferia reunirmo-nos mais tarde sem ele ${ }_{\mathrm{i}}$.

the João preferred.3SG meet.INF.1PL-self.1PL more late without him

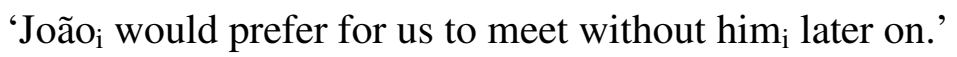

Notice that (38) only admits an uncontrolled reading, whereby the embedded null subject excludes João. Standard PC examples reject this reading precisely because the obligatory control relation leads to a violation of condition B (e.g., *John ${ }_{\mathrm{i}}$ preferred to meet without him $)$. In fact, two of the three speakers who accepted (36) also accepted (38) and the third one rejected it. The former speakers, then, analyze examples with person mismatch as standard pro-drop cases, which are irrelevant to the attempt to pin down the morphological properties of controlled PRO. It may well be the case that some or all of Sheehan's informants were similarly employing a non-control analysis of (36).

Suppose, however, that the single speaker in our survey who accepts (36) under a genuine OC analysis represents a real dialect. In this dialect, a DP specified $\left[3^{\text {rd }}, \mathrm{Sg}\right]$ can stand in a PC relation with a PRO specified $\left[1^{\text {st }}, \mathrm{pl}\right]$. That such a dialect exists, at least in BP, has been claimed by Modesto 2010a, who observes that the following example only admits a PC reading for him.

(39) O presidente preferiu nos reunir-mos na terça. the presdient preferred SELF meet.INF-1PL on.the Tuesday

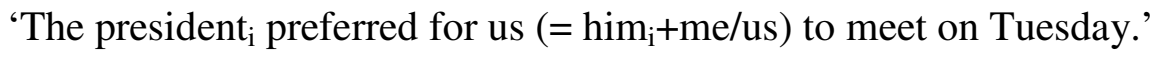

The question is whether the mismatches in the overt number/person values of the controller and PRO can be explained within the current analysis.

In fact, the analysis of Heim 2008, sketched above in (23), provides all we need. Just like the split-bound plural pronoun in (23a), the split-bound PRO in (36) and (39) more precisely, AM(i), where $i$ is PRO's index - consists of a bound part, inheriting [person:3] from the binder/controller, and a free part, picking the speaker or some 
group including the speaker. The resulting $\left[1^{\text {st }}, \mathrm{pl}\right]$ specification, dictated by $(23 \mathrm{~d})$, is reflected on the infinitival inflection. ${ }^{26}$

On this analysis, the Portuguese data do not challenge the idea that morphological features are transmitted from the controller to PRO in PC environments, but merely reflect the joint effect of this process and the person-resolution rule. Likewise, Portuguese inflected PC infinitives reveal the working of the number-resolution rule: PC PRO is not just semantically plural but also syntactically plural, unlike in English ((19) vs. (35)).

Neither do the Portuguese data challenge the idea that agreement applies at PF. While the AM is a syntactic affix that clearly feeds semantics, the shift it induces in the number (or person) features in the complement is not the result of agreement; clearly, the 1PL PRO in (39) does not agree with any matrix DP. Rather, PRO "sums up" the features received by transmission and those assigned contextually, and for all we know, this summing up could be either syntactic or morphological.

The special property of Portuguese, which is crosslinguistically rare and unusual, is the availability of inflected infinitives in OC complements. ${ }^{27}$ This option makes the AM component of PC PRO (situated in V, by hypothesis) morphologically visible to feature resolution algorithms, thus shifting both the syntactic number and, for some speakers, the person value of the controller, in accordance with the features of the group obtained by the AM. ${ }^{28}$ The resulting morphological shape of PRO matches its semantic denotation - a situation compatible with either the syntactic view of agreement (PRO's $\phi$-features are interpreted) or the PF view of agreement (PRO's $\phi$ features are uninterpreted). It is only by looking at English-type PC-complements (by far the common type) that we encounter the mismatch between form and meaning on PC PRO, decidedly favoring the PF view of agreement.

\footnotetext{
${ }^{26}$ Trivially, any composite pronoun is marked [plural].

${ }^{27}$ OC into inflected infinitives in European and Brazilian Portuguese has been documented before (Raposo 1989, Madeira 1994, Sitaridou 2002), and presents challenges that go beyond the present concerns. First, the very co-occurrence of agreement and (semantic) tense in OC complements is a typological anomaly (see Landau 2004, 2006, 2013a), to the point of suggesting a local, languageparticular solution. Second, the distribution of such inflected OC complements is lexically restricted in complex ways, even in those dialects that allow them (for recent analyses that begin to unravel these issues in Brazilian and European Portuguese, see Modesto 2010a, 2010b and Duarte, Gonçalves and Santos 2012, respectively). These problems might find a solution in a closer consideration of the special (and fragile) morphological status of the infinitival inflection, a topic that goes well beyond the goals of this paper.

${ }_{28}$ At the moment it is not clear to me why the shift in number is more systematic than the shift in person.
} 


\section{Theoretical Implications for the Theory of Control}

Adopting the PF view of agreement to control has several implications, which I touch on rather briefly in this section. Pursuing their consequences is a task I tackle in work in progress (Landau 2013b).

First, we saw that semantic as well as morphological evidence converges on the conclusion that PRO in OC is a bound variable. We have said nothing about its syntactic composition. The discussion points to a very bare element: a "reference variable", in the terms of Sigurðsson 2008, or a "minimal pronoun", in the terms of Kratzer 2009, whose $\phi$-values are filled-in only at PF. Syntactically, PRO may consist of a formal D features and unvalued $\phi$-features, [D, $\phi:]$. In PC, an AM is affixed to the verbal head of the complement, projecting a group out of the index of PRO. The details of the mechanism licensing this option remain to be specified.

If PRO is a bound variable, one must identify and study the nature of its binder. Where exactly is the $\lambda$-operator that binds PRO? Is it positioned in the matrix clause or in the complement clause? This latter is of course the mainstream view in the semantic literature on attitude reports and de se interpretations, which takes control complements to denote properties or sets of centered-worlds (Chierchia 1990, Percus and Sauerland 2003, Anand 2006, Pearson 2013). But notice that on this view, the agreement dependency between the matrix controller and PRO is mysterious. If PRO is bound by an operator in the complement clause and not by the ( $\lambda$-operator introduced by the) controller, how can we explain the fact that it is the controller that transmits its $\phi$-features to PRO - the main result of the present study? Given that on the standrad semantic treatments, the relation between the embedded operator and the controller is purely semantic (not even registered at LF), there seems to be no plausible way for it to effect agreement.

If, on the other hand, PRO is directly bound by the controller, the agreement facts follow smoothly. They would equally follow if control is represented as a predication dependency between the controller and the entire complement, as in Williams 1980, 1992; any standard theory of agreement provides some means of establishing subjectpredicate agreement. We thus conclude that at least from the perspective of the present discussion, either a variable-binding or a predication theory of control is wellsuited to handle the agreement relation between the controller and PRO. In fact, the two-tiered theory of control developed in Landau 2013b perfectly fits this bill. On this theory, verbs selecting non-attitude complements (like manage, decline and force) 
induce control by predication whereas verbs selecting attitude complements (like promise, persuade and intend) induce control by binding of a logophoric variable in the complement.

These cursory remarks, of course, are not intended as the final analysis of the phenomena at hand; rather, they aim to suggest that the issues raised by the conclusions of this paper are not new, and grammatical mechanisms exist that have been successfully applied to analogous cases elsewhere.

\section{Conclusion}

The argument developed in this paper aims to narrow down the architectural options concerning the locus of agreement in the grammar.

(40) a. Agreement applies at the syntactic component only.

b. Agreement applies either at the syntactic component or at PF.

c. Agreement applies at PF only.

We have seen that in certain (not uncommon) situations, the morphological features of PRO in PC are uninterpreted. Specifically, a group-denoting PRO that includes the speaker may nonetheless be specified [person:2] or [person:3], and one that includes the addressee may be specified [person:3]. The most natural way to explain the occurrence of uninterpreted $\phi$-features on a nominal element like PRO is to assume that they are valued at PF. Correspondingly, any agreement operation copying the $\phi$ values of PRO must also be a PF process, which pretty much covers all standard agreement dependencies involving A-positions.

On the basis of this argument, which is similar in spirit to Heim 2008 but drawing on quite independent evidence, we conclude that (40a) is false. Of the remaining two options, (40c) is more appealing than (40b), but the choice between them is still open. Data from inflected infinitives in Portuguese that initially appear to challenge this conclusion turn out to be neutral. In these constructions, the resolution of $\phi$-features on PC PRO results in the alignment of morphological and semantic values (systematically for [number], erratically for [person]); this, we speculated, is a 
consequence of the availability of inflected infinitives in OC environments. The Portuguese data are compatible with either (40a) or (40b).

The argument carries further implications for the proper semantic analysis of OC and the mechanism of feature transmission operative in these constructions, as well as the syntax of PC and the nature of null associative morphemes, some of which were briefly discussed as well.

\section{References}

Adger, David, and Daniel Harbour. 2007. Syntax and Syncretisms of the Person Case Constraint. Syntax 10, 2-37.

Anand, Pranav. 2006. De De se. PhD dissertation, MIT.

Asudeh, Ash. 2005. Control and Semantic Resource Sensitivity. Journal of Linguistics 41, 465-511.

Baltin, Mark R. 1995. Floating quantifiers, PRO and predication. Linguistic Inquiry 26, 199-248.

Barrie, Michael, and Christine M. Pittman. 2004. Partial Control and the Movement towards Movement. Toronto Working Papers in Linguistics 22, 75-92.

Bhatt, Rajesh, and Martin Walkow. Locating Agreement in Grammar: An Argument from Agreement in Conjunctions. To appear in Natural Language and Linguistic Theory.

Bobaljik, Jonathan. 2008. Where's Phi? Agreement as a Postsyntactic Operation. In Phi Theory: Phi-Features Across Modules and Interfaces, ed. by Daniel Harbour, David Adger and Susana Béjar, 295-328. Oxford, New York: Oxford University Press.

Bobaljik, Jonathan, and Idan Landau. 2009. Icelandic Control is not A-movement: The Case from Case. Linguistic Inquiry 40, 113-132.

Brame, Michael K. 1977. Alternatives to the Tensed s and Specified Subject Conditions. Linguistics and Philosophy 1, 381-411.

Bresnan, Joan. 1982. Control and Complementation. Linguistic Inquiry 13, 343-434.

Cabredo Hofherr, Patricia, and Brenda Laca. 2012. Verbal Plurality and Distributivity. Berlin: Walter de Gruyter.

Chierchia, Gennaro. 1990. Anaphora and Attitudes De Se. In Semantics and Contextual Expression, ed. by Renate Bartsch, Johan van Benthem and Peter van Emde Boas, 1-32. Dordrecht: Foris.

Chung, Sandra. 2012. On Reaching Agreement Late. In Proceedings of CLS 48, ed. by. Chicago: University of Chicago.

Corbett, Greville G. 2000. Number. Cambridge: Cambridge University Press.

Daniel, Michael, and Edith Moravcsik. 2005. The Associative Plural. In The World Atlas of Language Structures, ed. by Martin Haspelmath, Matthew S. Dryer, David Gil and Bernard Comrie, 150-153. Oxford: Oxford University Press.

Danon, Gabi. 2013. Agreement Alternations with Quantified Nominals in Modern Hebrew. Journal of Linguistics 49, 55-92. 
Darzi, Ali. 2008. On the VP Analysis of Persian Finite Control Constructions. Linguistic Inquiry 39, 103-115.

Dowty, David. 1985. On Recent Analyses of the Semantics of Control. Linguistics and Philosophy 8, 291-331.

Duarte, Inês, Anabela Gonçalves, and Ana Lúcia Santos. 2012. Control, Agreement and Temporal (In)dependence: An Argument for a Theory of Control as Agree. Paper presented at 38th Incontro di Grammatica Generativa, Verona, Italy.

Dubinsky, Stanley, and Shoko Hamano. 2007. A Window into the Syntax of Control: Event Opacity in Japanese and in English. In University of Maryland Working Papers in Linguistics, ed. by Anastasia Conroy, Chunyuan Jing, Chizuru Nakao and Eri Takahashi, 75-92. College Park, MD: UMPiL, Universoty of Maryland.

Evers, Arnold. 1988. Non-finite Verb Forms and Subject Theta Role Assignment. In Morphology and Modularity: In Honor of Henk Schultink, ed. by Martin Everaert, Arnold Evers, Riny Huybregts and Mieke Trommelen, 105-128. Dordrecht: Foris Publications.

Falk, Yehuda. 2006. Subjects and Universal Grammar. Cambridge: Cambridge University Press.

Fodor, Jerry A. 1975. The Language of Thought. Cambridge, MA: Harvard University Press.

Fox, Danny. 2000. Economy and Semantic Interpretation. Cambridge, MA: MIT Press.

Heim, Irene. 2008. Features on Bound Pronouns. In Phi Theory: Phi-Features Across Modules and Interfaces, ed. by Daniel Harbour, David Adger and Susana Béjar, 35-56. Oxford, New York: Oxford University Press.

Hornstein, Norbert. 2003. On Control. In Minimalist Syntax, ed. by Randall Hendrick, 6-81. Oxford: Blackwell Publishing.

Jackendoff, Ray, and Peter W. Culicover. 2003. The Semantic Basis of Control in English. Language 79, 517-556.

Jacobson, Pauline. 2012. Direct Compositionality and 'Uninterpretability': The Case of (Sometimes) 'Uninterpretable' Features on Pronouns. Journal of Semantics 29, 305-343.

Janke, Vikki. 2008. Control Without a Subject. Lingua 118, 82-118.

Karimi, Simin. 2008. Raising and Control in Persian. In Aspects of Iranian Linguistics, ed. by Simin Karimi, Donald Stilo and Vida Samiian, 177-208. Newcastle: Cambridge Scholars Publishing.

Landau, Idan. 2000. Elements of Control: Structure and Meaning in Infinitival Constructions. Dordrecht: Kluwer Academic Publishers.

Landau, Idan. 2004. The Scale of Finiteness and the Calculus of Control. Natural Language and Linguistic Theory 22, 811-877.

Landau, Idan. 2006. Severing the Distribution of PRO from Case. Syntax 9, 153-170.

Landau, Idan. 2008. Two Routes of Control: Evidence from Case Transmission in Russian. Natural Language and Linguistic Theory 26, 877-924.

Landau, Idan. 2013a. Control in Generative Grammar: A Research Companion. Cambridge University Press.

Landau, Idan. 2013b. Predication vs. Logophoric Anchoring: Integrating the Two Facets of Obligatory Control. Ms., Ben Gurion University.

Lasnik, Howard. 1995. Verbal Morphology: Syntactic Structures Meets the Minimalst Program. In Evolution and Revolution in Linguistic Theory: Essays in Honor 
or Carlos Otero ed. by Héctor Campos and Paula Kempchinsky, 251-275. Washington, D.C.: Georgetown University Press.

Madeira, Ana Maria. 1994. On the Portuguese Inflected Infinitive. UCL Working Papers in Lignuistics 6, 179-203.

Madigan, Sean. 2008. Control Constructions in Korean. PhD dissertation, University of Delaware.

Martin, Roger A. 1996. A Minimalist Theory of PRO and Control. PhD dissertation, UCONN.

McCloskey, James. 1991. There, It and Agreement. Linguistic Inquiry 22, 563-567.

Menuzzi, Sergio. 1999. Binding Theory and Pronominal Anaphora in Brazilian Portuguese. The Hague: LOT International Series.

Merchant, Jason. 2012. 'Deep' and 'Surface' Anaphora, Again. Ms., University of Chicago.

Modesto, Marcello. 2010a. What Brazilian Portuguese Says About Control: Remarks on Boeckx \& Hornstein. Syntax 13, 78-96.

Modesto, Marcello. 2010b. Control Structures With Inflected Infinitives in Brazilian Portuguese. Ms., Universidade de São Paulo.

Moravcsik, Edith A. 2003. A Semantic Analysis of Associative Plurals. Studies in Language 27, 469-503.

Morgan, Jerry L. 1970. On the Criterion of Identity for Noun Phrase Deletion. In Proceedings of CLS 6, ed. by Mary Ann Campbell et al., 380-389. Chicago: Chicago University Press.

Pearson, Hazel. 2013. The Sense of Self: Topics in the Semantics of De Se Expressions. $\mathrm{PhD}$ dissertation, Harvard University.

Percus, Orin. 2006. Antipresuppositions. In Theoretical and Empirical Studies of Reference and Anaphora: Toward the Establishment of Generative Grammar as an Empirical Science, ed. by Ayumi Ueyama, 52-73. Report of the Grantin-Aid for Scientific Research (B), Project No. 15320052, Japan Society for the Promotion of Science.

Percus, Orin, and Uli Sauerland. 2003. On the LFs of Attitude Reports. In Proceedings of Sinn and Bedeutung 7, ed. by Matthias Weisberger, 228-242. Konstanz: Universität Konstanz.

Pesetsky, David, and Esther Torrego. 2007. The Syntax of Valuation and the Interpretability of Features. In Phrasal and Clausal Architecture: Syntactic Derivation and Interpretation (In Honor of Joseph E. Emonds), ed. by Simin Karimi, Vida Samiian and Wendy K. Wilkins, 262-294. Amsterdam: John Benjamins.

Polinsky, Maria, and Eric Potsdam. 2001. Long-Distance Agreement and Topic in Tsez. Natural Language \& Linguistic Theory 19, 583-646.

Potsdam, Eric. 1997. English Verbal Morphology and VP Ellipsis. In Proceedings of NELS 27, ed. by Kiyomi Kusumoto, 353-368. Amherst: GLSA Publications.

Raposo, Eduardo. 1989. Prepositional Infinitival Constructions in European Portuguese. In The Null Subject Parameter, ed. by Osvaldo Jaeggli and Ken Safir, 277-305. Dordrecht: Kluwer.

Reuland, Eric. 2001. Primitives of Binding. Linguistic Inquiry 32, 439-492.

Reuland, Eric. 2010. Minimal versus Not So Minimal Pronouns: Feature Transmission, Feature Deletion, and the Role of Economy in the Language System. In The Linguistics Enterprise: From Knowledge of Language to Knowledge in Linguistics, ed. by Martin B.H. Everaert, Tom Lentz, Hannah 
De Mulder, Øystein Nilsen and Arjen Zondervan, 257-282. Amsterdam: John Benjamins.

Rodrigues, Cilene. 2004. Impoverished Morphology and A-movement out of Case Domains. PhD dissertation, University of Maryland.

Rodrigues, Cilene. 2007. Agreement and Flotation in Partial and Inverse Partial Control Configurations. In New Horizons in the Analysis of Control and Raising, ed. by William D. Davies and Stanley Dubinsky, 213-229. Dordrecht: Springer.

Rullman, Hotze. 2004. First and Second Person Pronouns as Bound Variables. Linguistic Inquiry 35, 159-168.

Safir, Ken. 2004. Person, Context and Perspective. Rivista di Linguistica 16, 107-153.

San-Martin, Itziar. 2004. On Subordination and the Distribution of PRO. PhD dissertation, University of Maryland.

Schlenker, Philippe. 2003. A Plea for Monsters. Linguistics and Philosophy 26, 29120.

Schlenker, Philippe. 2011. Indexicality and De Se Reports. In Semantics: An International Handbook of Natural Language Meaning, ed. by Klaus von Heusinger, Claudia Maienborn and Paul Portner, 1561-1604. Berlin: Mouton de Gruyter.

Sheehan, Michelle. 2012. A New Take on Partial Control: Defective Thematic Intervention. Ms., Cambridge University.

Sigurðsson, Halldór A. 2006. Agree in Syntax, Agreement in Signs. In Agreement Systems, ed. by Cedric Boeckx, 201-237. Amsterdam: John Benjamins.

Sigurðsson, Halldór A. 2008. The Case of PRO. Natural Language and Linguistic Theory 26, 403-450.

Sigurðsson, Halldór A. 2009. Remarks on Features. In Explorations of Phase Theory: Features and Arguments, ed. by Kleanthes K. Grohmann, 21-52. Berlin: Mouton de Gruyter.

Sitaridou, Ioanna. 2002. The Synchrony and Diachrony of Romance Infinitives With Nominative Subjects. PhD dissertation, University of Manchester.

Słodowicz, Szymon. 2007. Complement Control in Turkish. ZAS Papers in Linguistics 47, 125-157.

Spathas, Georgios. 2010. Focus on Anaphora. Utrecht: LOT.

Stechow, Arnim von. 2003. Feature deletion Under Semantic Binding. In Proceedings of NELS 33, ed. by Makoto Kadowaki and Shigeto Kawahara, 133-157. Amherst, MA: GLSA Publications.

Tallerman, Maggie. 1998. The Uniform Case-licensing of Subjects in Welsh. The Linguistic Review 15, 69-133.

Tóth, Ildikó. 2000. Inflected Infinitives in Hungarian. PhD dissertation, TILDIL, Tilburg University, Tilburg.

Wechler, Stephen. 2011. Mixed Agreement, the Person Feature and the Index/Concord Distinction. Natural Language \& Linguistic Theory 29, 9991031.

Wechsler, Stephen, and Larisa Zlatić. 2000. A Theory of Agreement and Its Application to Serbo-Croatian. Language 76, 799-832.

Wechsler, Stephen, and Larisa Zlatić. 2003. The Many Faces of Agreement. Stanford, CA: CSLI Publications.

Wilkinson, Robert. 1971. Complement Subject Deletion and Subset Relations. Linguistic Inquiry 2, 575-584.

Williams, Edwin. 1980. Predication. Linguistic Inquiry 11, 203-238. 
Williams, Edwin. 1992. Adjunct Control. In Control and Grammar, ed. by Richard Larson, Sabine Iatridou, Utpal Lahiri and James Higginbotham, 297-322. Dordrecht: Kluwer Academic Publishers.

Witkoś, Jacek, and Anna Snarska. 2009. On Partial Control and Parasitic PC Effects. SKASE Journal of Theoretical Linguistics 5, 42-75.

Wurmbrand, Susi. 2001. Infinitives: Restructuring and Clause Structure. New York: Mouton de Gruyter.

Wurmbrand, Susi. 2002. Semantic vs. Syntactic Control. In Proceedings of the 15th Workshop on Comparative Germanic Syntax, ed. by Jan Wouter Zwart and Werner Abraham, 93-127. Amsterdam: John Benjamins.

Wurmbrand, Susi. 2012. Agree(ment): Looking up or Looking down? Ms., UCONN. 